\title{
RADAR INTERFEROMETRY APPLICATION FOR DIGITAL ELEVATION MODEL IN MOUNT BROMO, INDONESIA
}

\author{
Noorlaila Hayati, Akbar Kurniawan, Muhammad Taufik \\ Geodynamic and Environment Laboratory \\ Department of Geomatics Engineering \\ Sepuluh Nopember Institute of Technology, Indonesia \\ Email : noorlaila@geodesy.its.ac.id
}

\begin{abstract}
This paper reviewed the result and processing of digital elevation model (DEM) using L-Band ALOS PALSAR data and two-pass radar interferometry method in Bromo Mountain region. Synthetic Aperture Radar is an advanced technology that has been used to monitor deformation, land cover change, image detection and especially topographic information such as DEM. We used two scenes of SAR imageries to generate DEM extraction which assumed there is no deformation effect between two acquisitions. We could derive topographic information using phase difference by combining two single looks complex $(S L C)$ images called focusing process. The next steps were doing interferogram generation, phase unwrapping and geocoding. DEM-InSAR was compared to SRTM 90m that there were significant elevation differences between two DEMs such as smoothing surface and detail topographic. Particularly for hilly areas, DEM-InSAR showed better quality than SRTM $90 \mathrm{~m}$ where the elevation could have $25.94 \mathrm{~m}$ maximum gap. Although the processing involved adaptive filter to amplify the phase signal, we concluded that InSAR $D E M$ result still had error noise because of signal wavelength, incidence angle, SAR image relationship, and only using ascending orbit direction.
\end{abstract}

Keywords: digital elevation model, ALOS PALSAR, radar, interferometry

\section{INTRODUCTION}

DEM is digital data showing geometric earth's surface from coordinate high points represented by regular grid or pixel raster and triangular irregular network (TIN). DEM can be made by using terrestrial survey such as laser scanning, total station, global position system (GPS), radar ground measurement and remote sensing such as photogrammetric, interferometry, radargrametry.

Applications of DEM are topography analysis, geomorphology particularly for slope, aspect, and volume, hydrology, land use classification, contour mapping, civil engineering, military and architecture (Purwanto, 2010). We used a case study in Mount Bromo, Probolinggo where is one of the most famous tourism area in East Java. Geomorphology information derived by DEM would be a significant role to help local government develop this area.

Generally, technology remote sensing is more popular to generate DEM because the production is more efficient than using ground survey. Radar interferometry is one of the advance techniques to produce DEM. The principle of DEM generation is how to get height values using interferometric phase information from two SLC images which have different time and orbit position (Sarmap, 2009). The advantages using radar interferometry to generate DEM are: the objects on the earth's surface are not distracted by cloud cover; and acquisition can still be used in night mode.

\section{DATA AND METHODS}

Two SAR imageries from ALOS PALSAR level 1.0 (Figure 1.) has been used in this research. Two acquisition times to derive DEM were on 2010.10.10 and 2010.11.25 date. The method that we used was two-pass interferometry. Generally, four main steps of DEM generation are data focusing, interferometric processing, phase unwrapped and phase to height conversion. 

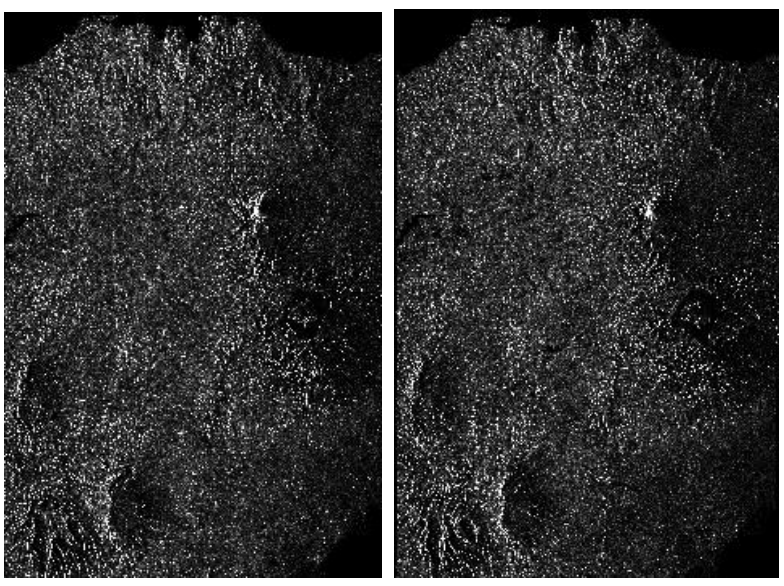

Fig. 1 SLC focusing images 2010.10.10 and 2010.11.25

The first time of processing is focusing raw SAR data included of amplitude and phase information to single look complex (SLC) data. Focusing has a purpose to combine the signal energy spread by duration of linear frequency modulation transmitted pulse called range and the length of the period illuminated by synthetic aperture called azimuth to be a single pixel. The detailed step of focusing is: Doppler centroid estimation, range compression, range migration, autofocus, DC ambiguity estimation and azimuth compression. Having two SLC, the next process were multi-looking processing to determine approximation of square pixel considering ground range resolution and space pixel on azimuth and co-registration processing needed to transform the slave image to the same as position pixel on master image.

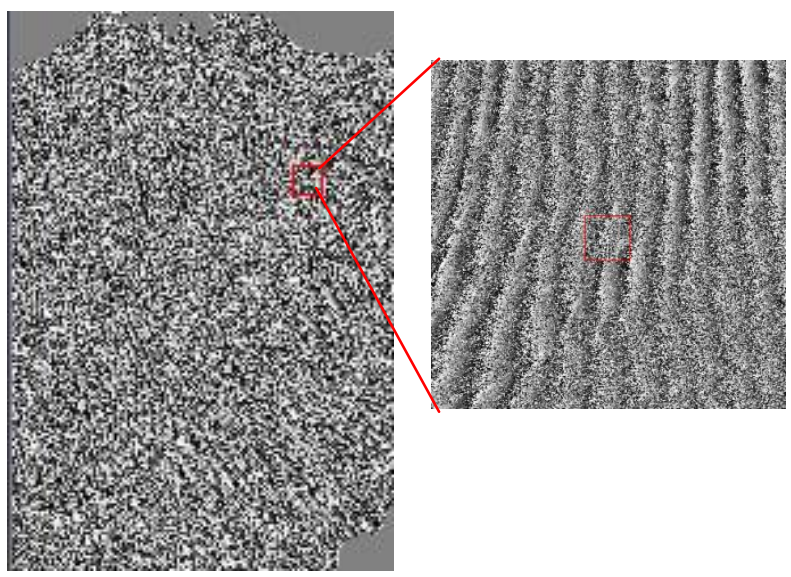

Fig. 2 Interferogram generation from a pair of SAR images
Secondly, interferogram generation with 85.112 $\mathrm{m}$ normal baseline value has been created and 90 $m$ DEM SRTM was used on this two-pass interferometry. The ratio of azimuth and range looks was 4:1. Because the interferogram still had topographic error, adaptive filter with boxcar type and coherence also need to be performed. Furthermore, we did phase unwrapping and correction parameter orbit using ground control point (GCP) distributed on all of scene to avoid fringe topography. This step include of refinement and flattening.

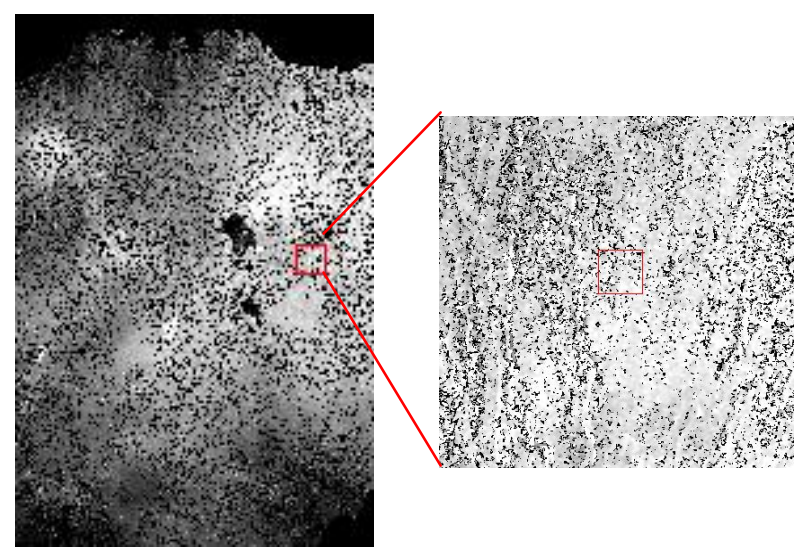

Fig. 3 Interferogram generation from a pair of SAR images

Finally, the last process was a conversion from phase to height and geo-coding. The projection map used to geo-code DEM result was Universal Time Mercator (UTM) on 49S zone and WGS84 for the ellipsoid reference.

\section{RESULT AND DISCUSSION}

The result showed on figure 4 that DEM has good performance to represent elevation in Mount Bromo. The dark color on the picture illustrates low height values and the bright color illustrates higher elevation. The brightest color correspondents to Mount Bromo and other mountain where are the highest places on region. 


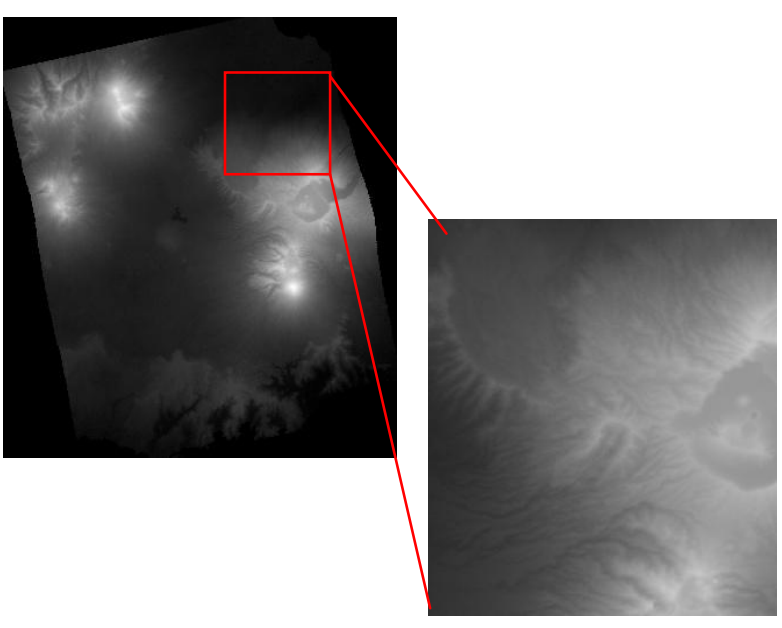

Fig. 4 DEM generation from radar interferometry ALOS PALSAR

This radar DEM has a spatial resolution of 15 meter and height resolution that commonly generated from SAR interferometry (InSAR) is about $5-10 \mathrm{~m}$. The ascending pair is one-repeat cycle or 46 days for ALOS PALSAR satellite.

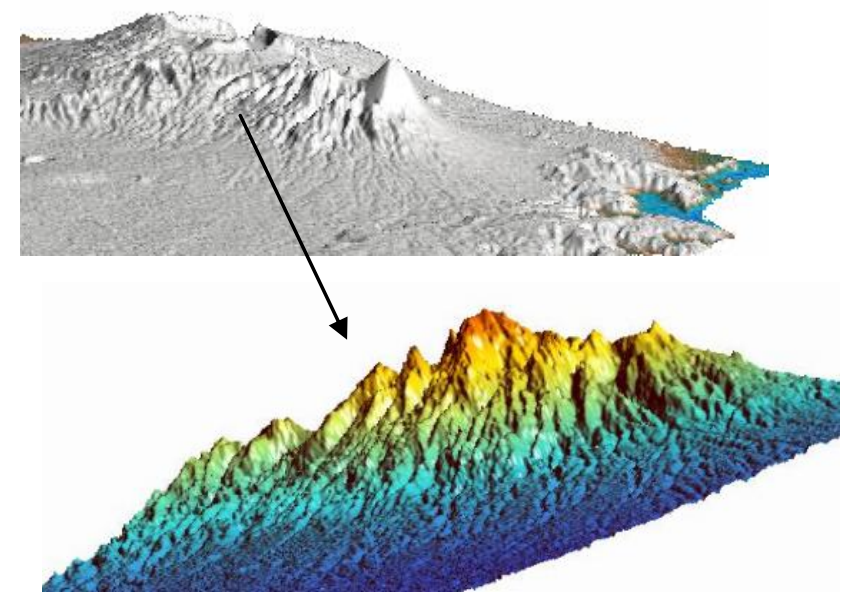

Fig. 5 DEM looked by 3D view

It is good to improve coherence with choosing short temporal baseline (Yu, 2010). However, the normal baseline was very short (85.112) while deriving good accuracy height of DEM needs longer perpendicular baseline.

According to terrain detail viewed by 3D (Figure 5.), flat area is not really smooth because topographic condition (Figure 6.) on Mount Bromo's surface has been covered by combination of sand and volcanic ashes that could make noise on backscattering result. Both on the flat area and the slopes of mountain have noise pattern because the error also came from deformation effect (Sasongko, 2010). For the information, Mount Bromo erupted on $26^{\text {th }}$ October 2010 and we used the master and slave images in range of eruption time.
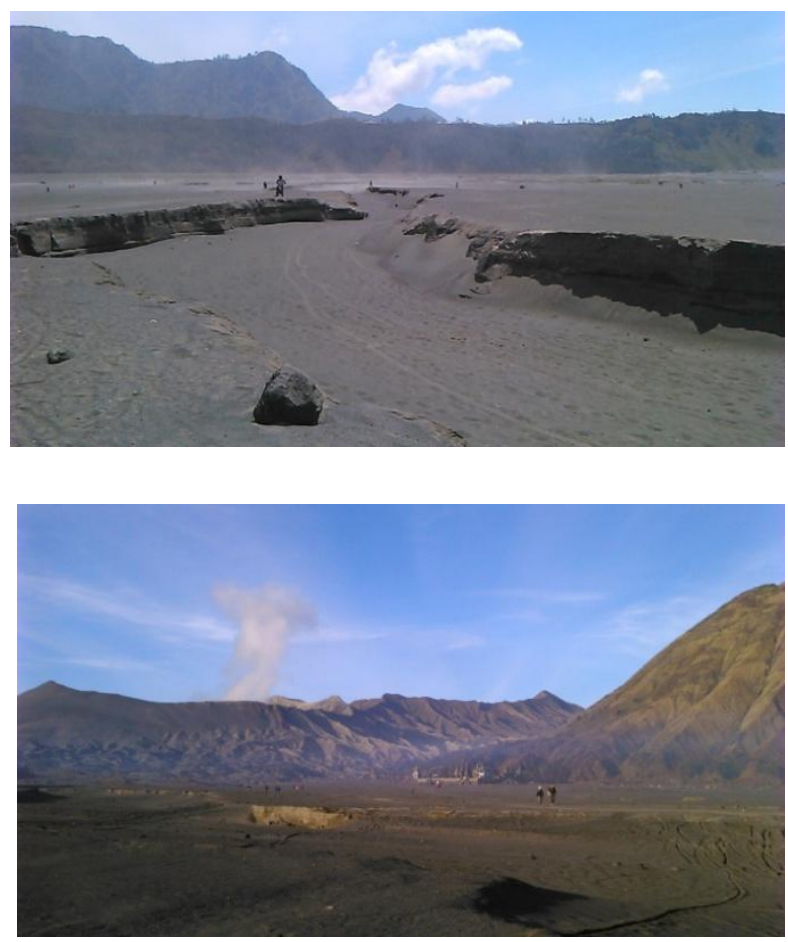

Fig. 6 Landscape of Mount Bromo, Indonesia

To know the quality of height resolution derived from radar DEM, we compared the result to $90 \mathrm{~m}$ SRTM which has one-pass interferometry technique using two-antennas on board. Line profiles on below pictures show the difference elevation between InSAR DEM with SRTM on flat and slope areas. From the graphics, we concluded that although there were significant different height values, DEM generation from SAR has same elevation pattern as SRTM.

Statistical review on slope area (dash line on figure 7.) shows that minimum height of InSAR DEM is $68 \mathrm{~m}$ and SRTM is $69 \mathrm{~m}$ while maximum height of InSAR DEM is $144 \mathrm{~m}$ and SRTM is $130 \mathrm{~m}$. InSAR DEM has better height resolution than SRTM DEM proved that InSAR DEM has more detail terrain than SRTM which tend to smooth. Nevertheless, SRTM DEM shows better quality on accuracy and precision due to smaller values on 
standard deviation $\left(\sigma_{\mathrm{SRTM}}=11.837\right)$ while InSAR DEM has $\sigma_{\text {SAR_DEM }}=16.321$. The greatest gap of high point is $25.94 \mathrm{~m}$ and the lowest gap is $0 \mathrm{~m}$. It means several points from slopes sample area have same elevation height. The average residual between two comparing DEMs is $5.85 \mathrm{~m}$.

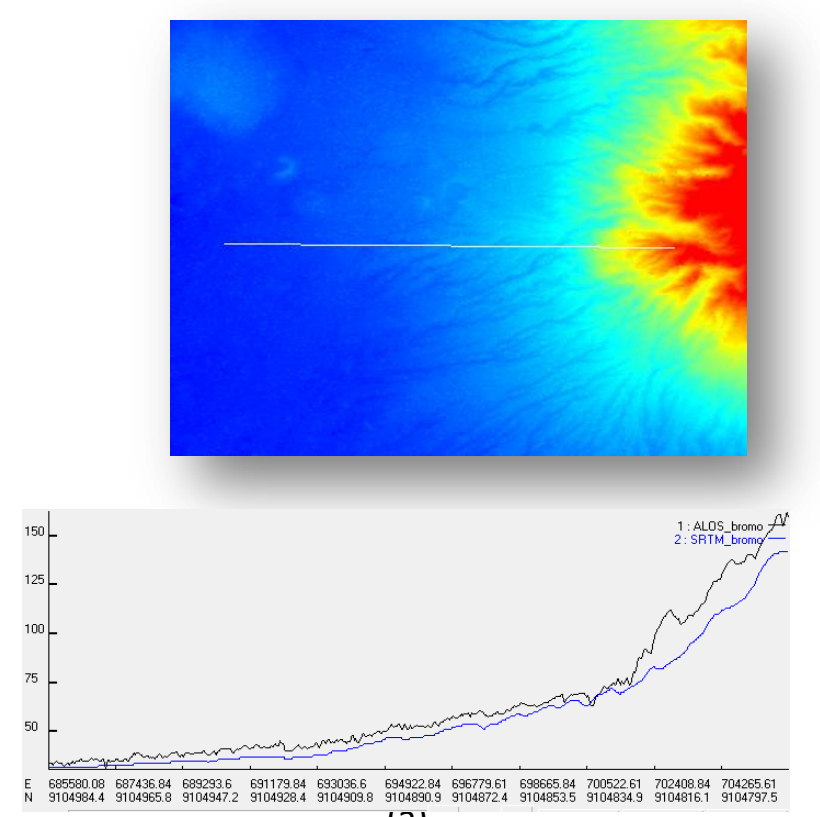

(a)
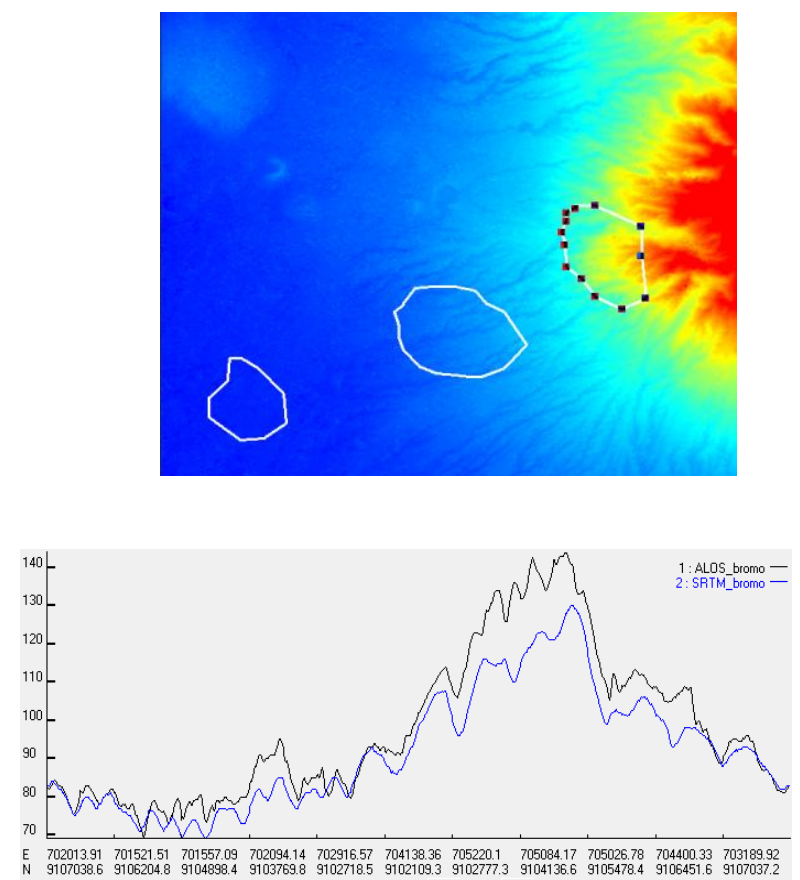

(b)

Fig. 7 Profiles on flat (a) and slope (b) areas showing the difference of InSAR DEM and SRTM
ALOS PALSAR is L band with $23.6 \mathrm{~cm}$ wavelength. The certain wavelength is good on vegetation canopies but not yet certainly on bare rough surface such as sand and volcanic ashes. Incidence angle also influences the quality of DEM related to error effects from shadowing, layover and foreshortening. Selection of pair images based on temporal and long baseline could make significant different result on each derived DEM since fringe pattern would be formed differently depending on its perpendicular baseline, orbit and look angle (Yu, 2010). Moreover, because we were only using ascending orbit direction, considering to geometric condition, slopes did not face the target area would have certain shadow effect error.

\section{CONCLUSION}

InSAR DEM is promising DEM generation which has more detail terrain and better spatial resolution. However, this research still need to be continue on verification with ground survey measurement which has more accurate elevation height on earth's surface. Comparing to SRTM, InSAR DEM has significant difference elevation with the average residual is 5.85 and maximum gap $25.94 \mathrm{~m}$ but the terrain produced by two DEMs presents similar pattern. The right selection of pair SAR images is important to avoid noise and error on SAR processing particularly related to temporal and long baseline. DEM generation is better using longer normal baseline due to effect base height ratio (Yu, 2010) and reduce effect atmospheric error (Hanssen, 2001).

\section{REFERENCES}

Purwanto, T.H, Digital Terrain Modeling. Yogjyakarta: Gadjah Mada University, 2010.

Sarmap. Synthetic Aperture Radar and SARScape. ITT Visual Information Solutions, 2009.

$\mathrm{Yu}$, Jung Hum and Ge, Linlin, Digital Elevation Model Generating Using Ascending and Descending Multi-baseline ALOS/PALSAR Radar Images. Sydney: FIG Congress, Facing the Challenges Building the Capacity, 2010.

Hanssen, R.F, Radar Interferometry. Data Interpretation and Error Analysis. Kluwer Academic Publishers. The 
Netherlands: Delft University of

Technology, 2001.

Hasegawa, Hiroyuki, et al, DEM Accuracy and The Best to Height $(B / H)$ Ratio of Stereo Images. Amsterdam: International Archives of Photogrammetry and Remote Sensing. Vol. XXXIII, Part B4. 2000.

Marinkovic, $\mathrm{P}$ and Hanssen, $\mathrm{R}$, InSAR Principles (Basic Tutorial), Nest SAR Training Course. ESA, 2009.

Ostir, Kristof., Stancic, Zoran., et al, Producing Digital Elevation Model with Radar Interferometry. Slovenia : Scientific Research Centre, Slovenian Academic of Sciences and Arts.

Fattahi, H., Amelung, F, DEM Error Correction in InSAR Time Series. IEEE Transactions on Geoscience and Remote Sensing, Vol. 51, No. 7, July 2013

Tarikhi, P, InSAR DEM; why it is better? Microwave Remote Sensing Research Group at the Mahdasht Satellite Receiving Station, Iran.

Sasongko, I. K, Pengamatan Deformasi Vertikal Permukaan Tanah Menggunakan Metode Interferometry SAR (InSAR). Surabaya: Teknik Geomatika, Institut Teknologi Sepuluh Nopember, 2011. 